\title{
NANOINDENTATIONS AS A LOCAL PROBE FOR THE MECHANICAL PROPERTIES AND ALLOYING INFLUENCES IN NICKEL-BASE SUPERALLOYS AND ALUMINIDE COATINGS
}

\author{
K. Durst, O. Franke, M. Göken \\ University Erlangen-Nuremberg, Materials Science and Engineering, Martensstr. 5, D-91058 Erlangen, Germany
}

Keywords: Nanoindentation, Aluminide Coatings, Platinum, Hardness, Young's modulus, Rhenium, NiAl, $\mathrm{PtAl}_{2}$

\begin{abstract}
Nanoindentation techniques have been applied to study the local mechanical properties of the three commercial single-crystalline nickel-base superalloys CMSX-6, CMSX-4 and CMSX-10 which have an increasing amount of rhenium and tungsten as well as to study the local mechanical properties of two platinum modified aluminide coatings, one having a single-phase NiAl structure and the other having a two-phase $\mathrm{NiAl} / \mathrm{PtAl}_{2}$ structure, in the ascoated condition and after thermo-mechanical fatigue testing. It was found, that the hardness of the $\gamma$-matrix in superalloys increases with the concentration of refractory elements, whereas only a small change in the hardness of the precipitates was found. The local mechanical properties of the coatings showed a strong correlation between aluminium concentration and structure on one hand and hardness and Young's modulus on the other hand. It was found that the hardness of the single-phase aluminide phase within the coating increases with decreasing aluminium concentration, whereas the modulus decreases. Furthermore, it was found that the two-phase coating has a very high hardness in the as-coated condition, which decreases significantly after TMFcycle due to the dissolving $\mathrm{PtAl}_{2}$-phase.
\end{abstract}

\section{Introduction}

Nanoindentation testing techniques have demonstrated in recent years its usefulness in the characterization of the local mechanical properties of individual phases in structural high temperature materials as nickel-base superalloys [1], TiAl-alloys [2] or molybdenum alloys [3]. Finite element simulations were performed to evaluate the mechanical properties from loaddisplacement curves reliably and to validate the experimental results by deriving load limits for indentation testing in two-phase materials [4]. Therefore it is now possible to use the nanoindentation technique to study alloying influences as for example solid solution hardening on a local scale of below 100 $\mathrm{nm}$, which is not possible by any other technique. In this work the micromechanical properties of different nickel-base superalloys and of aluminide coatings are studied quantitatively. Especially the alloying influence of Rhenium is investigated on bulk samples of different nickel-base superalloys, whereas for the coatings the influence of alloying elements and phase distribution on the mechanical properties is evaluated and compared with the thermomechanical fatigue life (TMF).

In the last 10 years, the addition of refractory elements, especially Rhenium, has led to an overall improvement of the mechanical properties of nickel-base superalloys. Monocrystalline nickel-base superalloys exhibit a two-phase microstructure consisting of a solid solution hardened fcc Ni-matrix (volume fraction $\geq 30 \%$ ) and $\gamma^{\prime}$-precipitates of the type $\mathrm{Ni}_{3} \mathrm{Al}$. The $\gamma$ - and $\gamma^{\prime}$-phases are hardened by refractory elements like rhenium, tungsten and tantalum. Rhenium and tungsten are known to solid solution strengthen the $\gamma$-matrix. Re partitions nearly to $100 \%$ in the matrix, whereas $\mathrm{W}$ partitions nearly evenly between $\gamma$ and $\gamma^{\prime}$, and Ta partitions preferably to the $\gamma^{\prime}$-precipitates. Atom probe investigations have shown that during growth of $\gamma$-particles, a pileup of Re solute atoms is formed at the $\gamma-\gamma$ ' interface and that Re-atoms form clusters in the $\gamma$-matrix, which hinders dislocation movement $[5,6]$. Moreover Re influences the lattice mismatch between $\gamma$ and $\gamma^{\prime}$-phase and reduces the coarsening rate of the $\gamma^{\prime}$ particles. $[7,8]$.

Additional to bulk materials, the micromechanical properties of different aluminide coatings are studied with nanoindentation. Since the aluminium concentration in nickel-base superalloys is too low to provide a good oxidation resistance of the surface at operation temperature, coatings are indispensable as protective means against the oxidative and corrosive attack of the superalloy components. Aluminide coatings on turbine airfoils, consisting of the intermetallic $\beta$-NiAl phase, are used to protect the surface of turbine blades against oxidation [9]. The coatings to be compared are two platinum modified aluminide coatings with single-phase and two-phase microstructure on specimens of the monocrystalline nickel-base superalloy CMSX-6. The coatings have been subject to thermo-mechanical fatigue (TMF), where a reduction in lifetime for the single-phase platinum coating of 1.5 2 and $4-6$ for the two-phase coating compared to the non-coated superalloy was found [10]. Thermo-mechanical fatigue (TMF) tests simulate typical loads experienced by the components in aero engines which are caused by simultaneous severe changes of temperature and stress during start-off and shut-down operation of the engine. Reasons for the reduced lifetime during TMF can be found in the low room temperature ductility of the intermetallic coatings. Aluminide coatings have been characterised for example by Wöllmer et al. [11]. Wöllmer et al. performed an extensive study on characterization of aluminide coatings on nickel-base superalloy in the as-coated condition with transmission electron microscopy as well as nanoindentation. They show, that the local microstructure and chemical composition within coatings is very inhomogeneous, and that phases with a high hardness precipitate during the coating process.

\section{Nanoindentation Experiments}

The microstructure of different superalloys was characterized with an atomic force microscope (AFM). Nanoindentation measurements were performed with an add-on force transducer from Hysitron Inc. and a Nanoindenter XP from MTS. The add-on 
force transducer, mounted on a conventional AFM, controls the zmovement of the tip and measures the indentation force [12]. In the nanoindenting AFM (NI-AFM), first the sample surface is imaged and after that a load-displacement curve is recorded during indenting at a specific position with the same diamond tip. The indents in the $\gamma$-matrix are bigger than the indents in the $\gamma$ 'phase, which can also be seen in the corresponding loaddisplacement curves which exhibit a larger indentation depth in the matrix at the same applied load (Fig. 1).
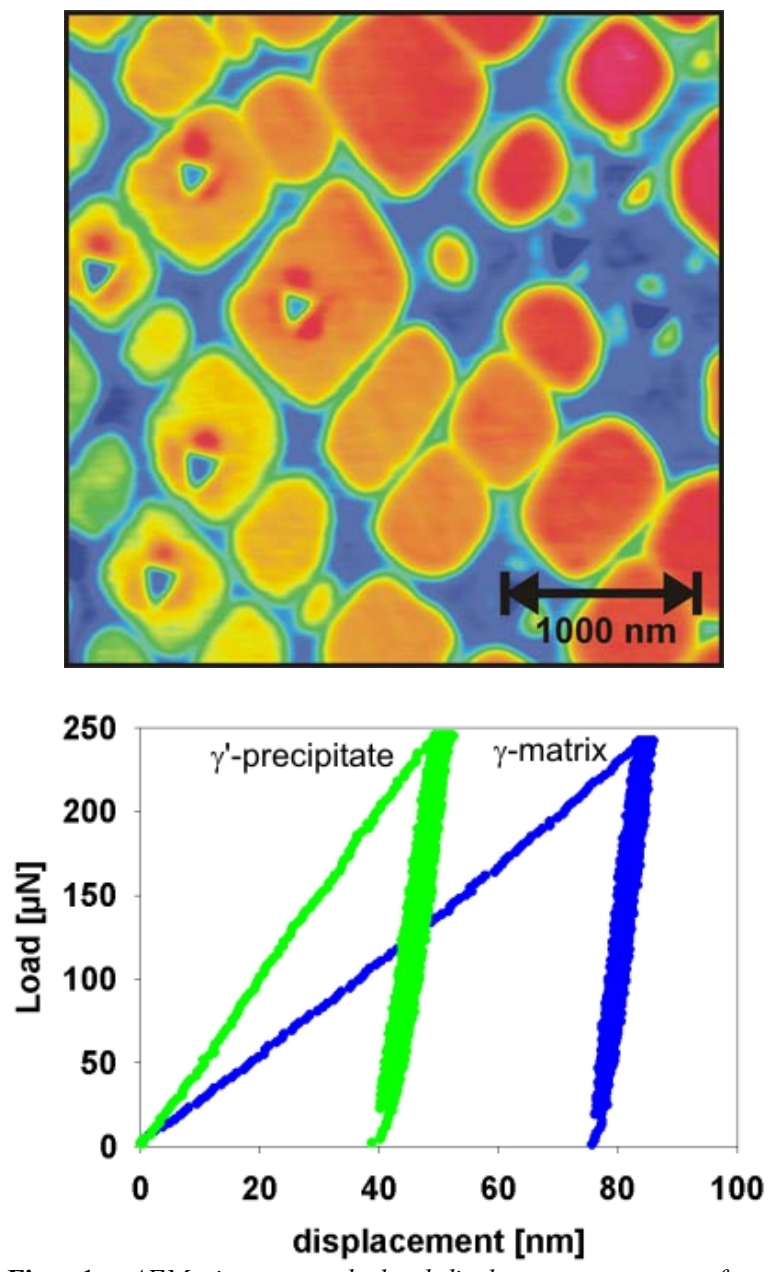

Fig. 1. AFM image and load-displacement curves from nanoindentation performed with the nanoindenting AFM in a nickel-base superalloy.

With nanoindentation techniques in general, the mechanical properties are calculated from a load-displacement curve recorded during indentation. The standard method for evaluating loaddisplacement curves was proposed by Olive\#r and Pharr [13]. The tip-shape function and the projected contact area $A_{\mathrm{c}}$ between the indenting tip and the material is calculated from the unloading part of the load-displacement curve. The contact stiffness $S$ for axisymmetric indenters and elastic isotropic half spaces is given by:

$$
S=\frac{\partial P}{\partial h}=2 E_{r} \sqrt{\frac{A_{C}}{\pi}}
$$

With the reduced elastic modulus $E_{\mathrm{r}}$ given as follows:

$$
\frac{1}{E_{r}}=\left(\frac{1-v^{2}}{E}\right)_{\text {Sample }}+\left(\frac{1-v^{2}}{E}\right)_{\text {Indenter }}
$$

The hardness is given by:

$$
H=\frac{P_{\max }}{A_{c}},
$$

where $P_{\max }$ is the maximum applied load, $\mathrm{P}$ the load and h the displacement.

The contact stiffness $S$ is determined by fitting a power law function at the beginning of the unloading part of the loaddisplacement curve or by using the continuous stiffness option of the Nanoindenter XP. A diamond tip with a cube-corner geometry (three-sided pyramid with an apex angle of $90^{\circ}$ ) was used for the indentation experiments on the nickel-base superalloys. The cubecorner geometry is better suited for studying the properties of small phases, like the matrix channels in nickel-base superalloys. A Berkovich tip was used to test the aluminide coatings. The Berkovich geometry has an equivalent tip area function as the Vickers pyramid and imposes a smaller strain to the indented area. The cube-corner and Berkovich tip were calibrated using fused silica as a reference material and the tip area function was monitored throughout the whole investigation. The machine compliance was taken into account.

The nanoindentation experiments on the aluminide coatings were performed using a Nanoindenter XP. In contrast to the NI-AFM, positioning of the indentation is done with an optical microscope. The machine is equipped with a continuous stiffness module, which applies an oscillating force at a frequency of about $45 \mathrm{~Hz}$ to the load during indentation. The contact stiffness is continuously evaluated during loading and hardness and reduced modulus are calculated using the Oliver/Pharr method as a function of indentation depth.

An increase in hardness with decreasing indentation depth is found for many metallic materials, which is referred to an indentation size effect. The indentation size effect can be related to the influence of geometrical necessary dislocations, where the dislocation density is proportional to the inverse of the indentation depth [14]. Oxide layers or work hardening of the surface caused by sample preparation are some of many additional factors which can lead to an increasing hardness at decreasing indentation depths. Therefore, the indentation measurements in the coatings were performed up to an indentation depth where the hardness stays constant. Indentations in the $\gamma / \gamma^{\prime}$-structure of the nickel-base superalloy are limited by the channel width of the matrix channels. The $\gamma^{\prime} / \gamma$-hardness ratio provides a useful means to quantify the hardening effects, under the assumption of similar indentation size effect on the hardness of both phases.

\section{Specimen preparation}

In the coating process, first a platinum layer with a thickness up to $25 \mu \mathrm{m}$ is electrochemically deposited and after that aluminium is deposited by chemical vapour deposition [15]. Cross sections of the coatings in initial condition and after a short and long TMF- 
treatment were investigated. Cross sections were prepared using a low speed diamond saw followed by conventional metallographic preparation method. Final polishing of the coatings as well as the nickel-base superalloys was done with a $0.05 \mu \mathrm{m}$ colloidal silica suspension.

The microstructure and chemical composition of the coatings was studied by scanning electron microscopy (SEM) and energy dispersive $\mathrm{x}$-ray spectroscopy (EDS). The average chemical composition was determined in rectangular areas perpendicular to the coating with a length of typically $30 \mu \mathrm{m}$ and a width of about $5 \mu \mathrm{m}$. The local chemical composition of individual phases was determined by spot analysis of at least five relatively large phases. Due to the high acceleration voltage, an influence of the surrounding material on the chemical analysis of the individual phases is given, especially at smaller precipitate size. The average size, aspect ratio and volume fraction of individual phases was determined from the SEM images.

\section{Local mechanical properties of nickel-base superalloys}

Three commercial single crystalline superalloys CMSX-6, CMSX-4 and CMSX-10 were investigated in detail as examples for the three generations of nickel-base superalloys, with zero and up to six wt.\% of Rhenium (see Table 1). The main difference between the alloys is the Re-concentration, starting from $0 \%$ for the first, $3 \%$ for the second and $6 \%$ for the third generation of superalloys. For the indentation measurements interdendritic and dendritic areas were distinguished and all the tests were performed in dendritic regions of the alloys. To account for the indentation size effect and tip shape influences, all measurements were performed with the same load of $250 \mu \mathrm{N}$ and the same tip Fig. 3. shows AFM-images of the typical $\gamma / \gamma^{\prime}$-microstructure with nanoindentations.
The hardness of the matrix phase increases with the concentration of the refractory elements, whereas only a small change in the hardness of the precipitates was found (see Fig. 2.). Especially the hardness ratio of precipitates to matrix is characteristic for each superalloy, starting at 1.31 for CMSX-10 up to 1.41 for CMSX-4 and 1.66 for CMSX-6. Moreover, the modulus of elasticity as measured by indentations performed with a Berkovich-tip increases with the concentration of refractory elements (Fig. 4).

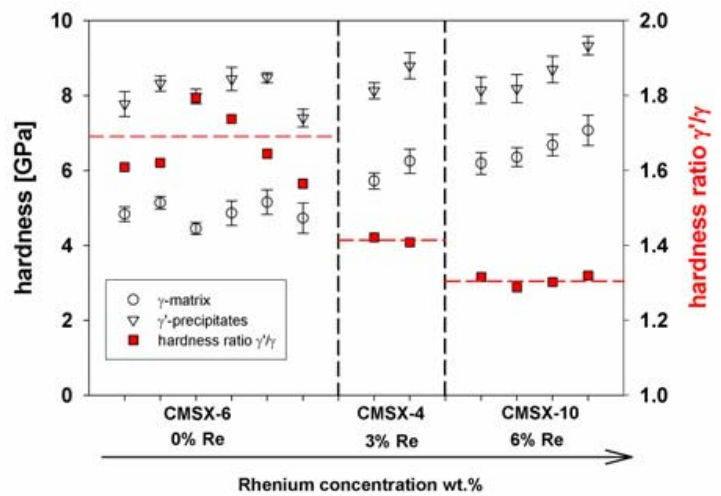

Fig. 2. Hardness and hardness ratio of $\gamma$ - and $\gamma$-phase in CMSX6, CMSX-4, CMSX-10. The hardness values are averaged for at least 10 indents in each phase. Different data points show measurements on different dendrites.
CMSX-6

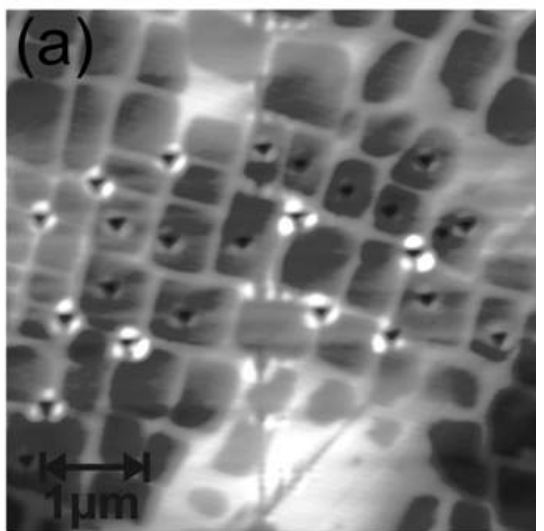

CMSX-4

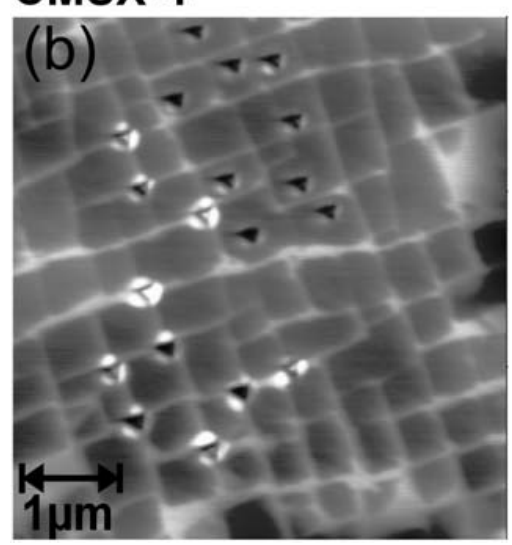

\section{CMSX-10}

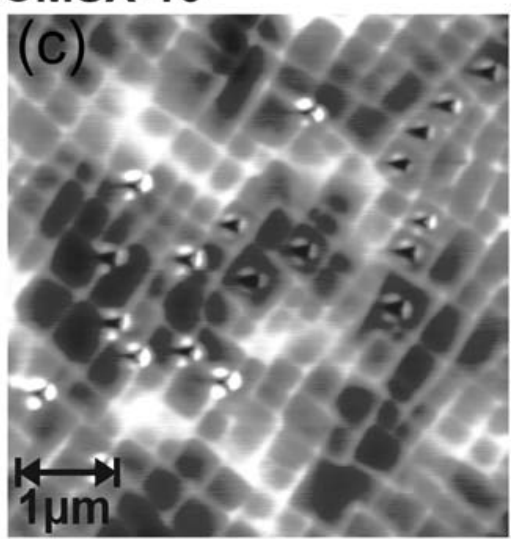

Fig. 3. Microstructure of the investigated nickel-base superalloys with nanoindentations in the $\gamma$-and $\gamma$ '-phase. The indents were performed with a cube-corner tip at a maximum applied load of $250 \mu N$. (a) CMSX-6, (b) CMSX-4, (c) CMSX-10.

Table 1. Nominal chemical composition of the investigated alloys in wt.\%.

\begin{tabular}{|c|c|c|c|c|c|c|c|c|c|c|}
\hline Alloy & $\mathrm{C}$ & $\mathrm{Cr}$ & $\mathrm{Mo}$ & $\mathrm{Ni}$ & $\mathrm{W}$ & $\mathrm{Co}$ & $\mathrm{Ti}$ & $\mathrm{Al}$ & $\mathrm{Ta}$ & $\mathrm{Re}$ \\
\hline CMSX-6 & 10 & 10.3 & 3.2 & bal. & - & 5.2 & 4.8 & 4.7 & 2.2 & - \\
CMSX-4 & - & 6.5 & 0.6 & bal. & 6.0 & 9.0 & 1.0 & 5.6 & 6.5 & 3.0 \\
CMSX-10 & - & 2.0 & 0.4 & bal. & 5.0 & 3.0 & 0.2 & 5.7 & 8.0 & 6.0 \\
\hline
\end{tabular}




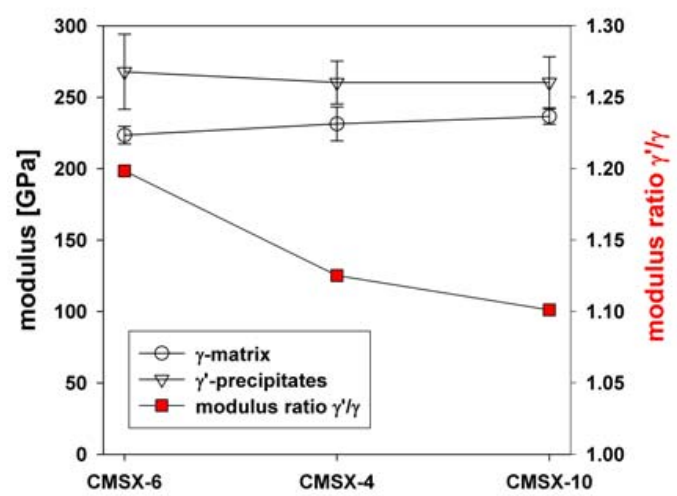

Fig. 4. Modulus of elasticity of $\gamma^{\prime} / \gamma$-Phase in CMSX-6, CMSX-4 and CMSX-10 as determined with the Oliver / Pharr method [13].

More details, also on indentation measurements on heat treated alloys can be found elsewhere [16]. These measurements show, that it is possible to determine solid solution hardening effects on a local scale. Therefore, the nanoindentation method was used to study similar effects in aluminide coatings, which are described in the following.

\section{Local mechanical properties of aluminide coatings}

Additionally to bulk materials, the micromechanical properties of different aluminide coatings on CMSX-6 were studied in the ascoated condition and after thermo-mechanical fatigue (TMF) cycling. A single and a two-phase coating were investigated. The single-phase coating mainly consists of the intermetallic $\beta$-NiAl phase with a relatively large grain size. The two-phase coating has a smaller grain size with the main constituents $\beta-\mathrm{NiAl}$ and $\mathrm{PtAl}_{2}$. During the coating process an interdiffusion process between substrate and coating takes place, which leads to the typical ascoated microstructure as shown in Fig. 8 and Fig. 9. It was found, that the single-phase coating is relatively ductile compared to the two-phase coating, which developed long and macroscopically straight cracks in an early state of TMF-cycling. Typically, the coatings have seen about $\mathrm{N}_{\mathrm{f}}=9200$ cycles until failure occurs. During TMF, an asymmetric cycle with a phase shift of $-135^{\circ}$ between the triangular signals of temperature and the mechanical strain with a strain ratio $\mathrm{R}=-1$ was used. Minimum and maximum temperatures for all tests performed were $400{ }^{\circ} \mathrm{C}$ and $1100{ }^{\circ} \mathrm{C}$, respectively. The heating and cooling rates were $10 \mathrm{~K} / \mathrm{s}$. More details on the TMF-behaviour of the coatings can be found elsewhere [10]. The phases NiAl and $\mathrm{PtAl}_{2}$ have been detected by $\mathrm{x}$-ray diffraction techniques (XRD) in the initial condition of the two-phase coating. After TMF-cycling only NiAl was detected in the coating [17].

The local properties of the coatings were determined by averaging the data of 9 indentations, performed on a line parallel to the surface (see Fig. 8). The spacing of $9 \mu \mathrm{m}$ between individual indents ensures that the indents are not influenced by each other. The continuous stiffness option of the Nanoindenter XP was used to determine depth dependent data on hardness and modulus in a depth range between $150 \mathrm{~nm}$ and $250 \mathrm{~nm}$. At this depth range, hardness and modulus are nearly independent of the indentation depth. Even at a higher indentation depth, up to $3 \mu \mathrm{m}$, no decrease in hardness was found in contrast to microindentation measurements on aluminide coatings performed by Ning et al [18]. Ning et al. used a similar preparation technique as in this study. However, only the indentations were performed using a Knoop-Indenter, which might explain the differences.

Hardness measurements

In the next diagrams, the hardness and modulus profiles of the individual coatings are shown. For comparison, all the data are plotted as a function of the normalized coating thickness. The scatter bars show the maximum and minimum hardness values. As reference values, indentation hardness and modulus of the bulk nickel-base superalloy (CMSX-6) is shown at an arbitrary chosen relative film depth of 2 . In most cases, a hardness value of $\sim 6 \mathrm{GPa}$ and a modulus of $\sim 220 \mathrm{GPa}$ is measured in the uncoated superalloy. Here, the hardness measurements averages over the $\gamma / \gamma$ '-structure.

In the initial condition of the single-phase coating the hardness in the cover layer is about $6.3 \mathrm{GPa}$ and reaches at a relative depth of about 1 a maximum hardness of 9.5 GPa (Fig. 5). A substantial increasing in hardness scattering is found at a relative depth of $0.85-1$, due to the occurrence of brittle phases within the coating.
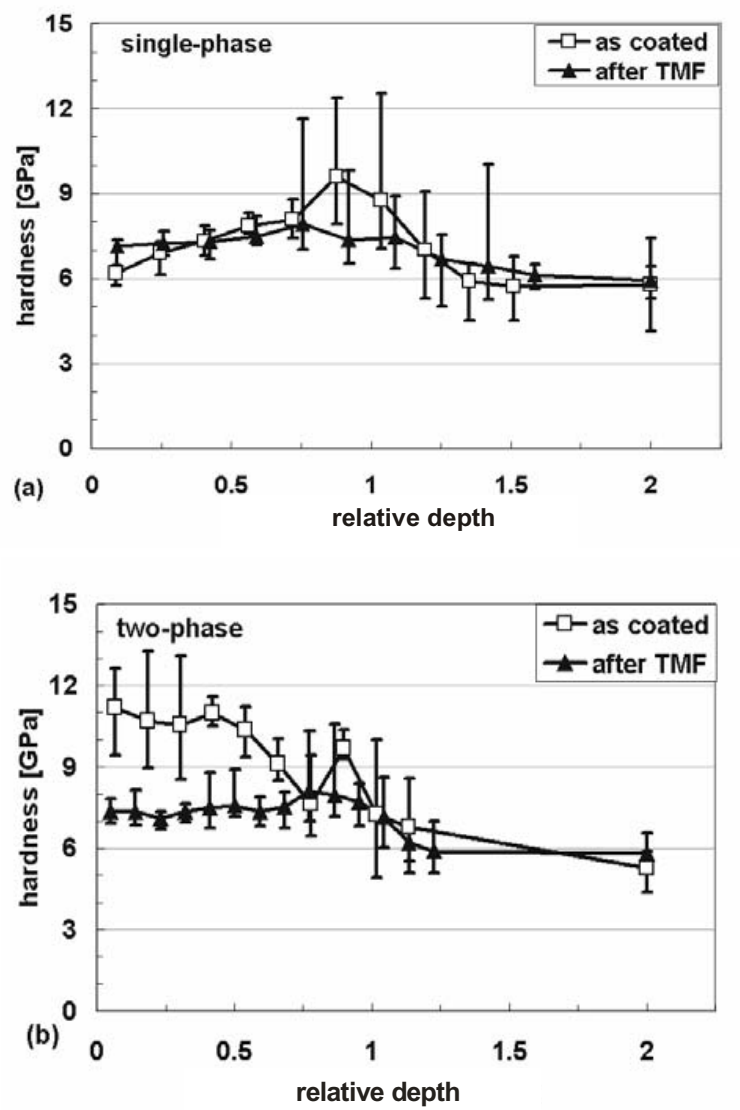

Fig. 5. Profiles of the local hardness as a function of the relative depth for the (a) single-phase and the (b) two-phase coatings in the as-coated and the TMF-tested conditions measured by nanoindentation. 
After TMF-loading, the hardness profile is relatively flat, compared to the initial condition and a value of $\sim 7.2 \mathrm{GPa}$ is found close to the surface. Due to brittle phases in the coating, a scattering in hardness values occurs at a relative depth of 0.75 . High hardness values are found at a depth $>1$ compared to the initial condition. The flattening of the hardness profile is related to the homogenization, which takes place during TMF-cycling.

In the initial condition of the two-phase coating, a much higher averaged hardness of $11.3 \mathrm{GPa}$ was found close to the surface (Fig. 5). At a relative depth of $\sim 0.75$, a sharp drop in the average hardness is obtained.

After TMF-cycling, the two-phase coating has a much smaller average hardness value compared to the initial condition. This hardness profile is similar to the single-phase coating in the initial condition

\section{Young's modulus measurements}

The modulus of the single-phase coating has an averaged value of $150 \mathrm{GPa}$ close to the surface in the initial condition and a value of 125 GPa after TMF-cycling (Fig. 6).

The modulus is nearly constant in the initial condition up to a relative depth of 0.5 and increases continuously up to the level of the nickel-base superalloy. After TMF-cycling, a slight increase in Young's modulus was found at the surface. Additionally, the modulus reaches the level of the nickel-base superalloy not before a relative depth of 1.2 .
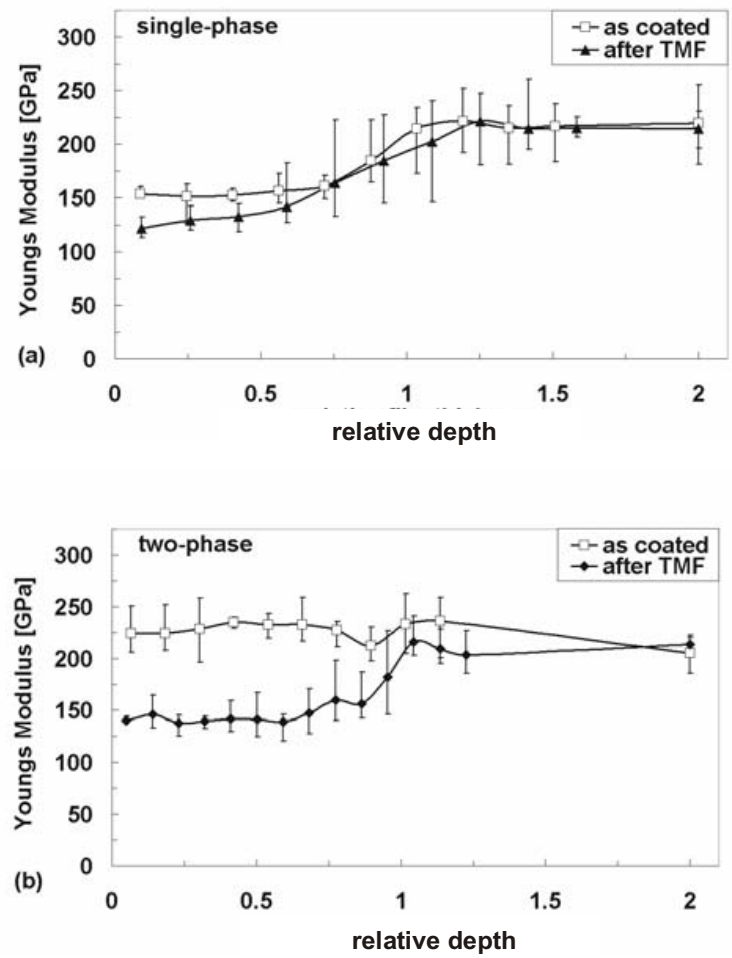

Fig. 6. Profiles of the local Young's modulus as a function of the relative depth for the (a) single-phase and the (b) two-phase coatings in the as-coated and the TMF-tested conditions measured by nanoindentation.
In the initial condition of the two-phase coatings, the modulus remains fairly constant at a level of about $225 \mathrm{GPa}$ (Fig. 6). After TMF-cycling, the profile in modulus resembles the one of the single-phase coating in the initial condition.

The coatings have some amount of porosity, especially after TMF-cycling (Fig. 8, Fig. 9). Indentations performed close to pores did not show any decrease in contact stiffness. Only in one case, where a pore was hit directly, a discontinuity in contact stiffness was observed. This measurement was excluded from the analysis.

Since always a low maximum indentation depth of $300 \mathrm{~nm}$ was applied, only single crystalline properties of the coatings are tested. To check, if the crystal orientation in the coatings has a significant effect on the measured modulus, the concept of the indentation modulus, as introduced by Vlassak and Nix is applied to the indentations performed in NiAl. Vlassak and Nix replaced the elastic modulus by the indentation modulus $\mathrm{M}$ and the reduced elastic modulus $\mathrm{E}_{\mathrm{r}}$ by the reduced indentation modulus $\mathrm{M}_{\mathrm{r}}$ in the case of elastic anisotropic elastic behavior [19]. NiAl has an elastic anisotropy factor $\mathrm{A}$ of 3.53 and a Poisson ratio of 0.31 [20]. Using the elastic constants $\mathrm{C}_{11}=199 \mathrm{GPa}, \mathrm{C}_{22}=136 \mathrm{GPa}$, $\mathrm{C}_{44}=114 \mathrm{GPa}$, the indentation modulus is calculated using the approach of Vlassak and Nix [21]. The calculation yields the following values: $\mathrm{M}_{<100>}=180.3 \mathrm{GPa}, \quad \mathrm{M}_{<110>}=202.1 \mathrm{GPa}$, $\mathrm{M}_{<111>}=208.6 \mathrm{GPa}$ and $\mathrm{M}_{\mathrm{P}}=198.7 \mathrm{GPa}$, where $\mathrm{M}_{\mathrm{P}}$ is the polycrystalline indentation modulus. Therefore the expected maximum difference of the measured indentation modulus for indentations in the soft $(<100>)$ and hard $(<111>)$ orientation of $\mathrm{NiAl}$ is at the order of $15 \%$. The indentation modulus of a non textured polycrystalline sample, with a relatively high anisotropy factor is close to the polycrystalline modulus. The effect of the elastic anisotropy of $\mathrm{NiAl}$ on the indentation modulus is therefore small and has no significant effect on the average Young's modulus as measured by nanoindentations.

Global chemical composition

To correlate the mechanical properties of the coatings with the aluminium content and the composition, the average local chemical composition was analyzed in similar areas where the indentations were performed as a function of the depth in the coating by EDX-analysis in the SEM (Fig. 7) [17].

For the ductile single-phase coating, an aluminium content of approximately 35 at.\% was detected in the as-coated condition. During TMF-cycling only slight microstructural changes were found and only small differences between the chemical concentrations. The platinum concentration lies between 5 at $\%$ and 8 at $\%$ for both coatings. The concentrations are not much affected by the TMF-cycling except for a homogenizing effect so that the platinum content is almost perfectly constant over the depth in the coating after the TMF test (Fig. 7.)

The two-phase coating shows a relatively high aluminium content of $54 \mathrm{at} \%$ in the as-coated condition, which decreases during TMF-cycling to a value of about $30 \mathrm{at} \%$. The chemical and microstructural stability of the two-phase coating during TMFcycling is relatively small. The initial platinum concentration of $8 \%$ is lowered to $2.8 \%$ after TMF-cycling and furthermore a homogenizing effect has taken place. 

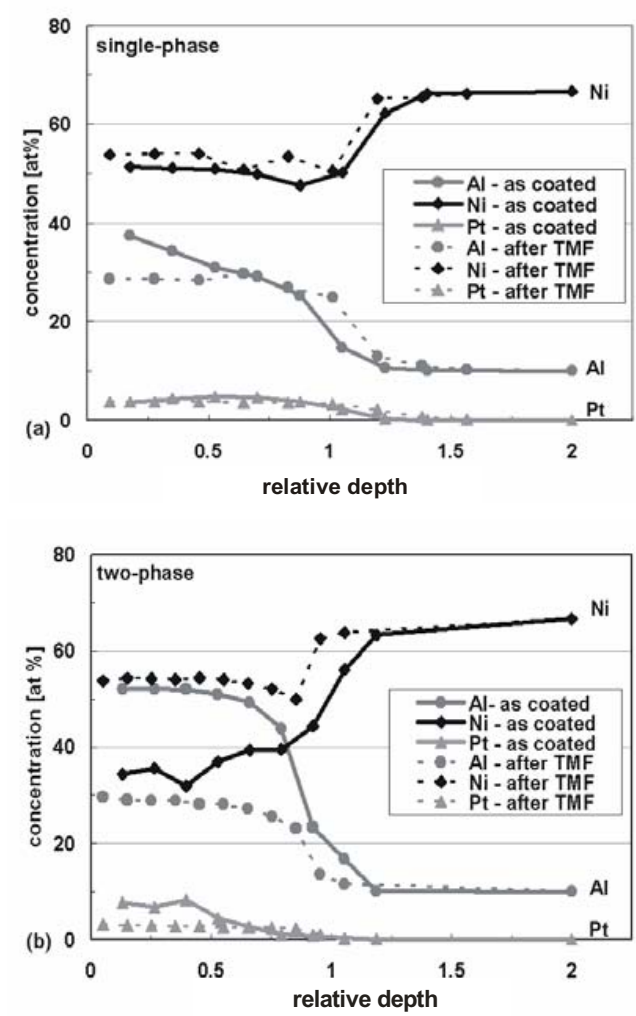

Fig. 7. Profiles of the concentrations of aluminium, nickel and platinum (as measured by energy dispersive spectroscopy in the scanning electron microscope) as a function of the depth in the coating for (a) single-phase and (b) two-phase coatings in the ascoated condition and after TMF-cycling. In all the cases, full lines show the concentration in the as-coated condition, whereas dotted lines show the concentration after TMF-cycling.

Additionally to the overall chemical composition, also the microstructure was analyzed in a SEM.

\section{Microstructural analysis of the coating}

Single-phase coating

In the cross section of the single-phase coating, at least two zones can be distinguished within the coating (Fig. 8): The single-phase NiAl cover-layer (zone 1) with an average grain size of about 45.6 $\mu \mathrm{m}$ and the interdiffusion zone. In zone 1, only a small scattering in hardness data is found.

Between zone 1 and zone 2 a region with a high porosity is observed. At the interface between the interdiffusion zone and the substrate, island-like areas with $\mathrm{Cr}$ - and Mo- rich needle-shaped precipitates were found. In the interdiffusion zone a volume fraction of about $12 \%$ of CrMo-rich phases and small $\mathrm{Ti}, \mathrm{Ta}, \mathrm{Si}-$ rich precipitates can be found. These precipitates also lead to the observed increase in scattering of the hardness measured in the interdiffusion zone. The chemical composition of the CrMo-phase and TiTa-phase in the interdiffusion zone is shown in Table 2.
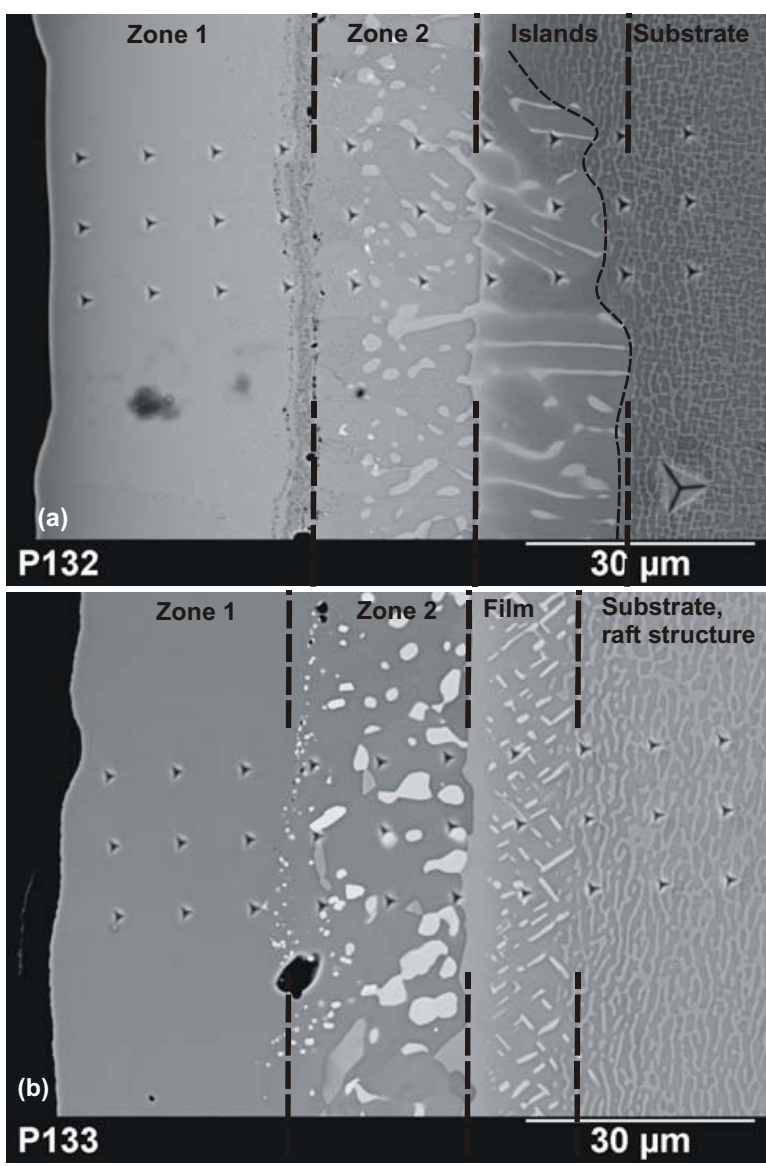

Fig. 8. Microstructure of the single-phase coating with nanoindentations in the (a) initial condition (P132) and (b) after TMF-cycling (P133) as imaged in the SEM in cross section (back scattered electron contrast).

Table 2: Chemical composition of the NiAl-, CrMo- and TiTa-phases in the single-phase coating in the as-coated condition and after TMF-cycling.

\begin{tabular}{|c|c|c|c|c|c|c|c|c|c|c|}
\hline Condition & Phase & $\mathrm{Al}$ & $\mathrm{Si}$ & $\mathrm{Ti}$ & $\mathrm{Cr}$ & $\mathrm{Co}$ & $\mathrm{Ni}$ & $\mathrm{Mo}$ & $\mathrm{Ta}$ & $\mathrm{Pt}$ \\
\hline As & $\mathrm{NiAl}$ & 26.7 & 0.7 & 5.4 & 8.0 & 3.8 & bal. & 0.7 & 0.2 & 4.1 \\
-coated & CrMo & 3.5 & 1.6 & 1.4 & 42.7 & 7.8 & bal. & 17.0 & 0.1 & 1,3 \\
& $\mathrm{TiTa}$ & 7.8 & 7.0 & 25.9 & 7.5 & 2.3 & bal. & 2.5 & 21.1 & 1.9 \\
\hline After & NiAl & 27.6 & 0.6 & 3.3 & 6.9 & 3.5 & bal. & 0.5 & 0 & 3.6 \\
TMF & CrMo & 1.5 & 1.3 & 0.5 & 44.0 & 8,7 & bal. & 20.2 & - & 0.9 \\
& TiTa & 6.3 & 7.2 & 30.6 & 3.5 & 1.7 & bal. & 0.7 & 26.2 & 1.1 \\
\hline
\end{tabular}


Table 3 shows the volume fraction, maximum diameter and aspect ratio of the different phases as determined from SEM images by the line intersection method in the different zones of the singlephase coating in the initial condition. The aspect ratio is defined as the maximum length of a precipitate divided by the minimum length determined perpendicular to the maximum length axis.

After TMF-cycling, some changes in the structure of the singlephase coating are found. Again, two zones can be distinguished in the cross section: The coarse grained single-phase NiAl cover layer and the interdiffusion zone, which has now a higher volume fraction of CrMo-precipitates.

Table 3. Volume fraction, diameter and aspect ratio of the different phase in the single-phase coating P132 in initial condition. * Due to the small size of the TiTa precipitates, only approximate numbers are given.

\begin{tabular}{|c|c|c|c|c|}
\hline Zone & Phase & $\begin{array}{c}\text { Volume } \\
\text { fraction }\end{array}$ & $\begin{array}{c}\text { Grain size / } \\
\text { diameter }\end{array}$ & $\begin{array}{c}\text { Aspect } \\
\text { ratio }\end{array}$ \\
\hline 1 & $\mathrm{NiAl}$ & $100 \%$ & $45,6 \mu \mathrm{m}$ & - \\
\hline \multirow{2}{*}{2} & $\mathrm{NiAl}$ & $87 \%$ & $9.86 \mu \mathrm{m}$ & 1.52 \\
& $\mathrm{CrMo}$ & $12 \%$ & $2.4 \mu \mathrm{m}$ & 2.51 \\
& $\mathrm{TiTa}^{*}$ & $1 \%$ & $0.7 \mu \mathrm{m}$ & 1.5 \\
\hline Islands & $\mathrm{CrMo}$ & $8.9 \%$ & $4.9 \mu \mathrm{m}$ & 6.5 \\
\hline
\end{tabular}

Between zone 1 and the interdiffusion zone, a necklace of TiTaprecipitates is formed. The islands grew together and form now a film with a thickness of $\sim 12.6 \mu \mathrm{m}$ on nearly the whole length of the coating, still including the needle-shaped CrMo-precipitates. The needle (plate) like shaped particles are now oriented at an angle of $45^{\circ}$ to the coating. In the superalloy, a rafted structure, running parallel to the coating interface has been developed. The corresponding quantitative data on the volume fraction, diameter and aspect ratio of the different phases in the different zones can be found in Table 4.

Table 4. Volume fraction, diameter and aspect ratio of the different phase in the single-phase coating P133 after TMFcycling.

\begin{tabular}{|c|c|c|c|c|}
\hline Zone & Phase & $\begin{array}{c}\text { Volume } \\
\text { fraction }\end{array}$ & $\begin{array}{c}\text { Grain size / } \\
\text { diameter }\end{array}$ & $\begin{array}{c}\text { Aspect } \\
\text { ratio }\end{array}$ \\
\hline 1 & $\mathrm{NiAl}$ & $100 \%$ & $39.7 \mu \mathrm{m}$ & 1.16 \\
\hline \multirow{2}{*}{2} & $\mathrm{NiAl}$ & $84 \%$ & $10.9 \mu \mathrm{m}$ & 1.6 \\
& $\mathrm{CrMo}$ & $16 \%$ & $3.53 \mu \mathrm{m}$ & 1.9 \\
& TiTa* & $1 \%$ & $0.84 \mu \mathrm{m}$ & 1.6 \\
\hline Islands & $\mathrm{CrMo}$ & $15 \%$ & $3.4 \mu \mathrm{m}$ & 10.42 \\
\hline
\end{tabular}

The chemical composition of the NiAl-, CrMo- and TiTa-phase in the interdiffusion zone (zone 2) is shown in Table 2.

\section{Two-phase coating}

In the cross section of the two-phase coating in the as-coated condition, three zones are distinguished (Fig. 9). First the twophase $\mathrm{NiAl} / \mathrm{PtAl}_{2}$ cover-layer, with a relative small grain size of about $5 \mu \mathrm{m}$. Secondly a zone of single-phase NiAl with grain size close to $20 \mu \mathrm{m}$ and third the interdiffusion zone.
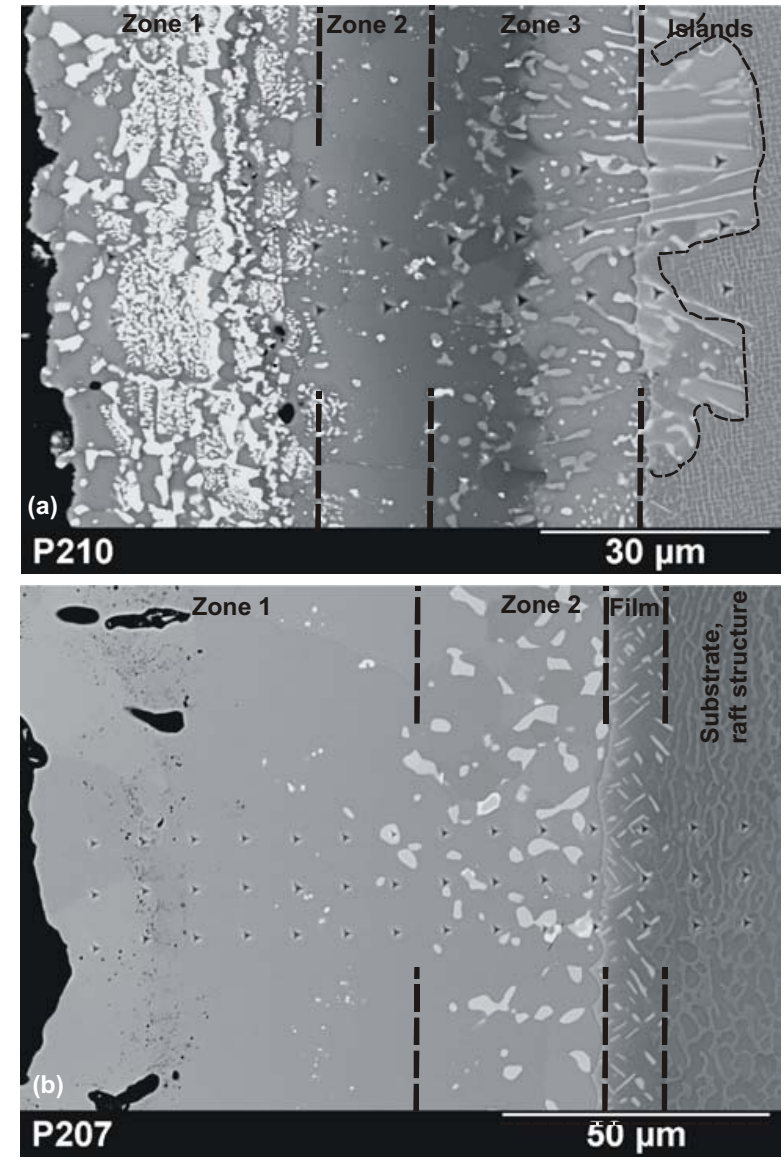

Fig. 9. Microstructure of the two-phase coating with nanoindentations in the (a) initial condition (P210) and (b) after TMF (P207) as imaged in the SEM in cross section (back scattered electron contrast). Please note the different magnification used in (a) and (b).

Table 5. Volume fraction, diameter and aspect ratio of the different phase in the two-phase coating P210 in the initial condition. * Due to the small size of the precipitates, only approximate numbers are given and the chemical composition could not be determined.

\begin{tabular}{|c|c|c|c|c|}
\hline Zone & Phase & $\begin{array}{c}\text { Volume } \\
\text { fraction }\end{array}$ & $\begin{array}{c}\text { Max. } \\
\text { Diameter }\end{array}$ & $\begin{array}{c}\text { Aspect } \\
\text { ratio }\end{array}$ \\
\hline \multirow{2}{*}{1} & $\mathrm{NiAl}$ & $38 \%$ & $5.5 \mu \mathrm{m}$ & 1.22 \\
& $\mathrm{PtAl}_{2}$ & $62 \%$ & $2.0 \mu \mathrm{m}$ & 2.24 \\
\hline \multirow{2}{*}{2} & $\mathrm{NiAl}^{*}$ & $94 \%$ & $20.0 \mu \mathrm{m}$ & 1.3 \\
& $\mathrm{PtAl}_{2}{ }^{2}$ & $6 \%$ & $1.2 \mu \mathrm{m}$ & 1.8 \\
\hline \multirow{2}{*}{3} & $\mathrm{NiAl}$ & $85 \%$ & $9 \mu \mathrm{m}$ & 2.3 \\
& $\mathrm{CrMo}$ & $15 \%$ & $3.0 \mu \mathrm{m}$ & 5.77 \\
\hline Islands & $\mathrm{CrMo}$ & $11 \%$ & $5.3 \mu \mathrm{m}$ & 14.93 \\
\hline
\end{tabular}

The high scattering in minimum and maximum hardness values is due to the $\mathrm{NiAl} / \mathrm{PtAl}_{2}$ two-phase microstructure of zone 1 . The observed sharp drop in hardness at a relative depth of 0.75 correlates exactly with the occurrence of single-phase NiAl in zone 2 . In the zone 2 a small volume fraction of small precipitates occur, which could not be analyzed, but which are 
most probably $\mathrm{PtAl}_{2}$-precipitates. The interdiffusion zone is characterized by a volume fraction of about $15 \%$ of CrMophases. Again, island like areas with needle- or plate-shaped CrMo-precipitates were found. The corresponding quantitative data on the volume fraction, diameter and aspect ratio of the different phases in the different zones can be found in Table 5 .

After TMF-cycling, the microstructure and properties of the twophase coating resembles the single-phase coating in the initial condition. The $\mathrm{PtAl}_{2}$ phase is dissolved in the cover layer and a coarse grained NiAl layer with grain size of $20 \mu \mathrm{m}$ is found. In the XRD-pattern, only NiAl can be identified [17].

Within the NiAl layer a necklace of TiTaSi-phases with a size of about $0.7 \mu \mathrm{m}$ becomes visible. In the interdiffusion zone CrMoand TiTaSi-containing phases can now be found. In the nickelbase superalloy a raft structure parallel to the coating interface has developed. The islands in the superalloy now form a film with a thickness of $\sim 10.9 \mu \mathrm{m}$ on nearly the whole length of the coating, still including the needle-shaped CrMo precipitates. The corresponding data on the volume fraction, diameter and aspect ratio of the different phases in the different zones can be found in Table 6.

Table 6. Volume fraction, diameter and aspect ratio of the different phase in the two-phase coating P207 after TMF-cycling.

\begin{tabular}{|c|c|c|c|c|}
\hline Zone & Phase & $\begin{array}{c}\text { Volume } \\
\text { fraction }\end{array}$ & $\begin{array}{c}\text { Grain size } / \\
\text { diameter }\end{array}$ & $\begin{array}{c}\text { Aspect } \\
\text { ratio }\end{array}$ \\
\hline 1 & NiAl & $100 \%$ & $18.5 \mu \mathrm{m}$ & 1.2 \\
\hline \multirow{2}{*}{2} & NiAl & $92 \%$ & $12.0 \mu \mathrm{m}$ & 1.28 \\
& CrMo & $7 \%$ & $3.2 \mu \mathrm{m}$ & 1.9 \\
& TiTa* & $1 \%$ & $0.7 \mu \mathrm{m}$ & 1,5 \\
\hline Islands & CrMo & $8 \%$ & $3.2 \mu \mathrm{m}$ & 7,1 \\
\hline
\end{tabular}

The chemical composition of the NiAl-, $\mathrm{PtAl}_{2}-$, CrMo- and TiTaphases in the interdiffusion zone is shown in Table 7.

Local properties of individual phases / precipitates

Closer examination of the nanoindentation data allows also determination of the properties of individual precipitates. In Fig. 10, the profiles of hardness and modulus for indentations performed in P207 are shown.

The data showing the highest modulus and hardness were collected from an indention on the CrMo-rich phase. Calculating hardness and modulus between an indentation depth of $50 \mathrm{~nm}$ and $100 \mathrm{~nm}$ yields a hardness value of $16 \mathrm{GPa}$ and a modulus of $262 \mathrm{GPa}$. At higher indentation depths, the measured data are influenced by the surrounding material and only the averaged mechanical properties of the indented material were measured. The curves with a modulus of $150 \mathrm{GPa}$ were performed in the same row as the indent in the hard CrMo-rich phase and show an average constant hardness of about $7.5 \mathrm{GPa}$ in this region, with an average modulus of about $150 \mathrm{GPa}$. The lowest hardness value of $5.3 \mathrm{GPa}$ was determined from an indent performed in the rafted structure of the nickel-base superalloy, yielding a modulus of about $200 \mathrm{GPa}$.
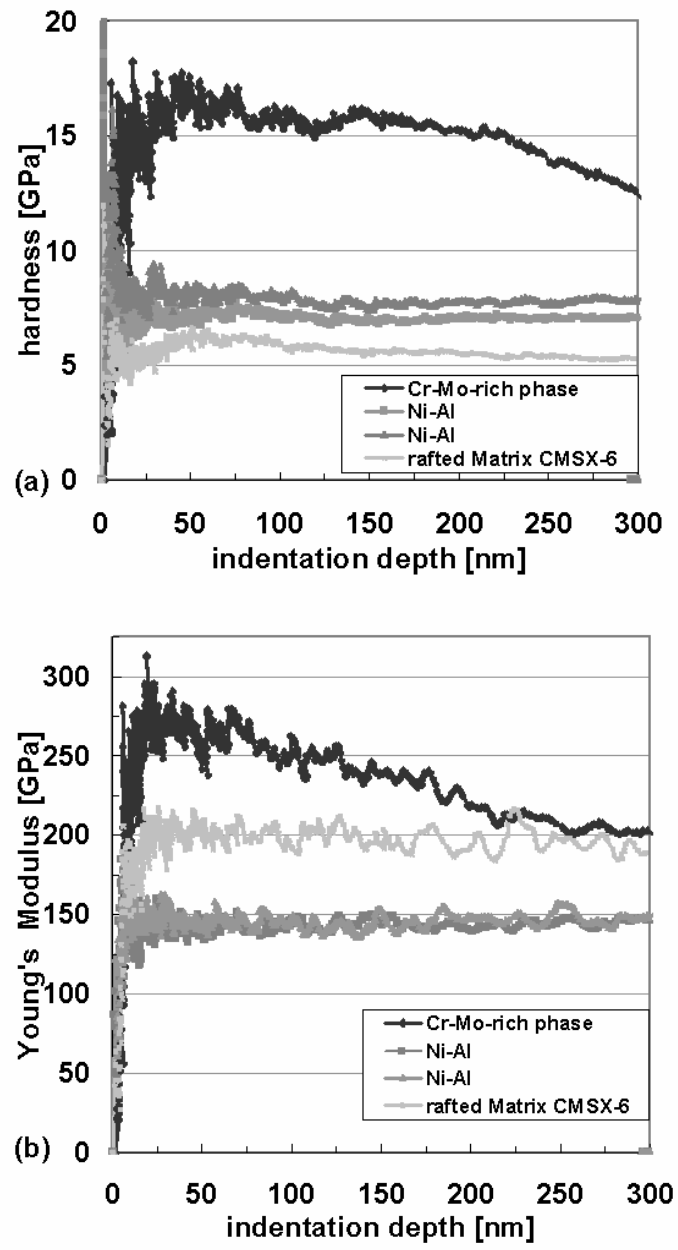

Fig. 10. (a) Hardness and (b) modulus as a function of indentation depth for individual indents performed up to a maximum indentation depth of $300 \mathrm{~nm}$.

Table 7. Chemical composition of the NiAl-, PtAl $2_{2}^{-}, \mathrm{CrMo}$ - and TiTa-phases in the two-phase coating in the as-coated condition and after TMF-cycling

\begin{tabular}{|c|c|c|c|c|c|c|c|c|c|c|}
\hline Cond. & Phase & $\mathrm{Al}$ & $\mathrm{Si}$ & $\mathrm{Ti}$ & $\mathrm{Cr}$ & $\mathrm{Co}$ & $\mathrm{Ni}$ & $\mathrm{Mo}$ & $\mathrm{Ta}$ & $\mathrm{Pt}$ \\
\hline $\mathrm{As}$ & $\mathrm{NiAl}$ & 27.8 & 0.9 & 11.0 & 5.4 & 4.3 & bal. & 0.4 & 0.9 & 0.7 \\
-coated & $\mathrm{PtAl} \mathrm{I}_{2}$ & 48.5 & 0.8 & 2.0 & 3.6 & 2.9 & bal. & 0.8 & 0.7 & 2.1 \\
& $\mathrm{CrMo}$ & 6.6 & 1.4 & 4.4 & 56.3 & 2.5 & bal. & 10.6 & - & 0.3 \\
\hline After & $\mathrm{NiAl}$ & 28.2 & 0.6 & 4.2 & 6.3 & 3.6 & bal. & 0.5 & 0.3 & 2.8 \\
$\mathrm{TMF}$ & $\mathrm{CrMo}$ & 1.7 & 2.0 & 0.8 & 42.6 & 8.0 & bal. & 22.1 & 0.1 & 0.6 \\
& $\mathrm{TiTa}$ & 4.3 & 6.8 & 30.2 & 6.5 & 2.2 & bal. & 2.4 & 28.1 & 0.5 \\
\hline
\end{tabular}




\section{Discussion}

The local mechanical properties as measured by nanoindentations can be related to the overall chemical composition and local microstructure within the coatings. The properties are important for the observed life reduction during TMF-cycling.

Fig. 11 compares the hardness and modulus of the single-phase and the two-phase coating in the initial condition and after TMFcycling.
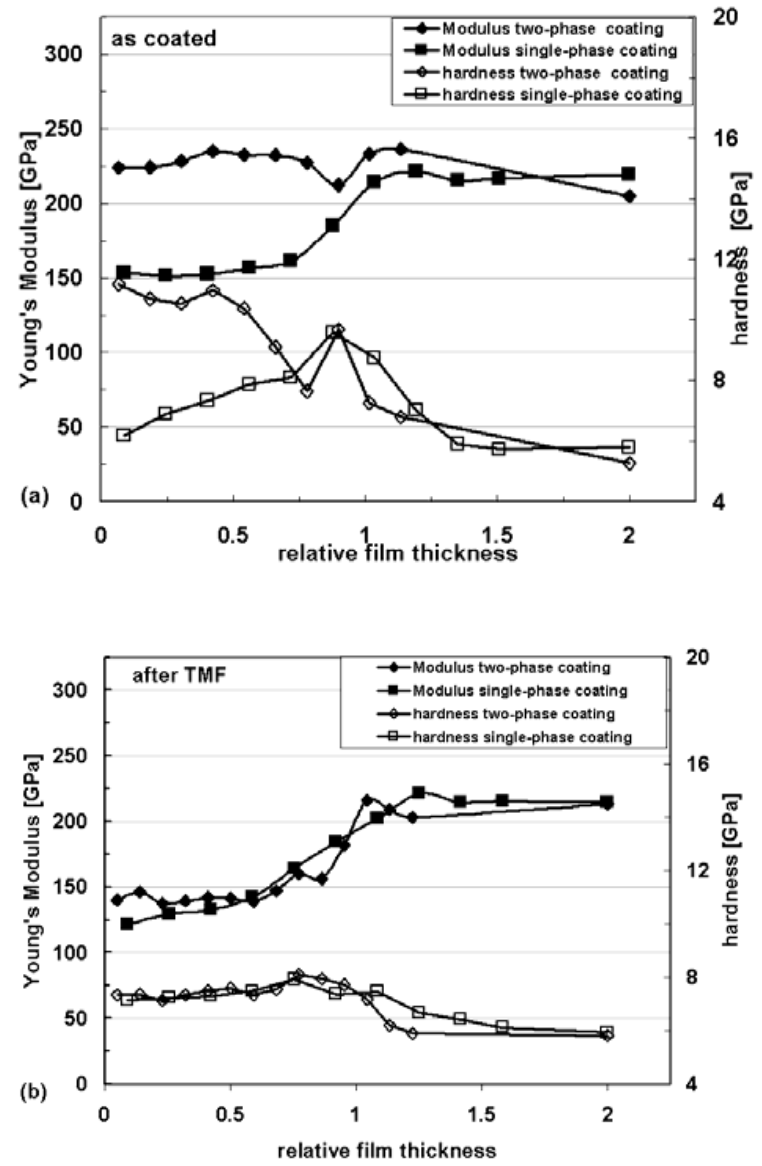

Fig. 11. Profiles of the hardness and Young's modulus as a function of the relative film depth for the (a) as-coated condition and the (b) TMF-tested conditions for the two-phase and singlephase coating, measured by the nanoindentation method.

The two-phase coatings show a high microstructural instability, which results in the dissolving of the two-phase $\mathrm{NiAl} / \mathrm{PtAl}_{2}$ structure to single-phase NiAl after TMF-cycling. The corresponding hardness in the formerly two-phase zone of the coating is now lowered to the value of single-phase NiAl. The high hardness in the as-coated condition is also related to the twophase NiAl / PtAl2 microstructure, which also indicates a low ductility of the coating (see Fig. 9). Since the two-phase coating fractures early because of its limited ductility, the subsequently expected enhancement of the ductility as a consequence of the loss of the two-phase structure during TMF-cycling has no useful practical implication. The decrease of aluminium concentration and moreover the loss of the two-phase structure after TMFcycling, leads to a decrease in the indentation modulus from 225 $\mathrm{GPa}$ to about $145 \mathrm{GPa}$.

The results on the evolution of the microstructure during TMFcycling of the two-phase coating presented here are in accordance with Moretto et al, who studied two-phase platinum modified coatings in the as-coated condition and after TMF-cycling [22]. Moretto et al. also reports the dissolving of the two-phase structure during TMF and finds also raft structure within the nickel-base superalloy being parallel to the coating-bulk interface. In the present work, fine details of the microstructure could be resolved and were quantified and related to the local mechanical properties measured by the nanoindentation method.

The effect of aluminium concentration on the properties of $\mathrm{NiAl}$ can be discussed for the single-phase coating close to the surface, where no precipitations occur (Fig. 8). For bulk NiAl-samples, a strong effect of the aluminium concentration on the elastic properties of $\beta$-NiAl within the range of homogenity has already been shown by Rusovic and Warlimot by determination of the frequency of vibration [23]. Depending on temperature, they find a Young's modulus of about $175 \mathrm{GPa}$ at an aluminium content of 55 at $\%$ which decrease to $\sim 120 \mathrm{GPa}$ at an aluminium content of 38 at $\%$. The nanoindentation results show a similar correlation between the aluminium concentration and the indentation modulus for the single-phase coating. There, a slight decrease and averaging of the aluminium content (Fig. 7a) after TMF-cycling of the single-phase coating close to the surface results in a decrease in indentation modulus (Fig. 6a). The hardness on the other hand is close to the surface nearly constant after TMF, corresponding to the constant aluminium concentration, whereas in the initial condition, at a higher aluminium concentration a lower hardness was found (Fig. 5a). This would also imply a higher ductility for a higher aluminium content, which is not consistent with Affeldt [9], who finds, that the fracture strain of aluminide coatings increases with a decreasing aluminium content. This problem is not yet resolved, because at the moment, no unique relation between hardness, modulus and fracture strain as a function of the aluminium content of aluminide coatings has been developed.

\section{Conclusion}

The present study shows the application of nanoindentation as a tool to study the micromechanical properties in the $\gamma / \gamma^{6}$-structure of three nickel-base superalloys CMSX-6, CMSX-4 and CMSX10 and of two modified aluminide coatings subjected to thermomechanical fatigue

In the superalloys, an increasing Re concentration results in an increasing hardness of the $\gamma$-matrix, whereas no difference in the hardness of the $\gamma$ '-precipitates could be found.

It has been shown, that nanoindentation is a method to determine modulus and hardness as a function of local composition and structure in coatings and on nickel-base superalloys.

The microstructure of the coatings and their chemical composition was quantified. It was found, that the hardness and modulus of the single-phase NiAl zones in the coatings is strongly influenced by the aluminium concentration. With decreasing aluminium concentration, a decrease in hardness and an increase in Young's modulus could be measured. 
The hardness of the two phase $\mathrm{NiAl} / \mathrm{PtAl}_{2}$ zones within the coatings was significantly higher than the hardness of the singlephase NiAl zones, indicating a much lower ductility of the twophase structure.

\section{Acknowledgment}

The authors thank H. Mughrabi, E. E. Affeldt and F. Grube for the many helpful discussions and for supplying the coated fatigue samples in the as-coated condition and after TMF-cycling. The fatigue samples were obtained in a framework project funded by MTU through E. E. Affeldt. Financial support of the BMBF under contract Hot Topics 03N8631B for the study on the local properties of the nickel-base superalloys is also gratefully acknowledged.

\section{References}

1. M. Göken, M. Kempf, Acta mater. 47 (1999) 1043.

2. M. Göken, M. Kempf, and W.D. Nix, Acta mater. 49 , (2001) 901

3. M. Göken, R. Sakidja, W.D. Nix and J.H. Perepezko, Mat Sci. Eng. A 319 (2002) 902.

4. K. Durst, M. Göken, and H. Vehoff, J. Mater. Res. 19 (2004) 85.

5. P.J. Warren, A. Cerezo, G.D.W. Smith, Mater. Sci. Eng. A 250 (1998) 88.

6. D. Blavette, P. Caron, T. Khan, Superalloys 1988, The Metallurgical Society, Warrendale, PA (1988) 305.

7. A. F. Giamei, Anton D. L. Metall. Trans. 16 A (1985) 1997.

8. A. Epishin, U. Brückner, P.D. Portella, T. Link, Scripta Mater. 48 (2003) 455.

9. E.E. Affeldt, Transactions of the ASME, Journal of Engineering for Gas Turbines and Power, 121 (1998) 687.

10. F. Grube, E.E. Affeldt, H. Mughrabi in Proc. of the fifth international conference on low cycle fatique, LCF5, Berlin, Germany in press (2003)

11. S.Wöllmer, S. Zaefferer, M. Göken, T. Mack, U. Glatzel, Surf. Coat. Tech. 167 (2003) 83.

12. M. Kempf, M. Göken, Z. Metallkd 92 (2001) 1061

13. W. C. Oliver, G. M. Pharr, J. Mater. Res. 7 (1992) 1564.

14. W. D. Nix, H. Gao, J. Mech. Phys. Sol. 46 (1998) 411.

15. J. R. Nicholls, JOM (2000) 28.

16. K. Durst, M. Göken, Mater. Sci. Eng. A accepted for publication (2004)
17. F. Grube, $\mathrm{PhD}$ thesis, University Erlangen-Nuremberg (2003)

18. B. Ning, M. E. Stevenson, M.L. Weaver, R.C. Brandt, Surf. Coat. Tech. 163 (2004) 112.

19. J.J. Vlassak, W.D. Nix, J. Mech. Phys. Solids. 42 (1994) 1223.

20. D. B. Miracle, Acta metall. mater. 41 (1993) 649.

21. M. Göken, Habilitation thesis, Saarland University, Der Andere Verlag, Osnabrück, (2002)

22. P. Moretto, J. Bressers, D. J. Arrel, Mater. Sci. Eng. A 272 (1999) 310 .

23. N. Rusovic, H. Warlimont, Phys. Stat. sol. 53 (1979) 283 